\title{
Distribuição eletrônica na hotelaria: um estudo de caso do Hotel Casa de Praia, Fortaleza (CE)
}

\author{
Distribution channels in hotel industry: a case study on Beach \\ House Hotel Fortaleza (CE, Brazil)
}

\author{
Fabrício Silva Barbosa
}

\section{RESUMO}

Os canais de distribuição adquiriram uma importante função dentro do mix de marketing, pois contribuem de forma significativa na competitividade das empresas no mercado, em especial do segmento hoteleiro. Os canais eletrônicos de distribuição aparecem como grandes ferramentais disponíveis que facilitam a distribuição dos serviços prestados pelos hotéis ao consumidor final. É importante salientar que o aumento significativo da utilização de canais de marketing na hotelaria impõe um grande desafio aos empresários do segmento. Há a necessidade de se adaptar a uma ferramenta de negócios que em alguns momentos contribuem e em outros momentos competem com os próprios empreendimentos. Esta investigação teve como objetivo analisar os canais de distribuição utilizados por um hotel de pequeno porte localizado na cidade de Fortaleza/CE. De caráter qualitativo e exploratório, o método empregado foi o estudo de caso, que teve como objeto de estudo o Hotel Casa de Praia. Os resultados da pesquisa ratificam a predominância de canais de distribuição eletrônicos como principais ferramentas de distribuição do empreendimento estudado. A pesquisa evidencia a consolidação da distribuição eletrônica como umas das principais ferramentas de negócios utilizadas atualmente pelo setor hoteleiro.

PALAVRAS-CHAVE: Canais de Distribuição; Marketing; Hotelaria; Fortaleza.

\begin{abstract}
Distribution channels play an important role in the marketing mix, as they make a significant contribution to the competitiveness of companies in the market, particularly in the hotel sector. Electronic distribution channels are important tools that facilitate the distribution of services provided by hotels, to the final customer. It is noteworthy that the significant increase in the use of marketing channels in hotel industry poses a great challenge to business segment. There is a need to adapt to a business tool that has occasionally contribute and at other times compete with the developments themselves. This qualitative, exploratory study analyzes the distribution channels used by a small hotel. It uses the case study method, taking as its object of study the Hotel Casa de Praia. The research results show that for the business studied, electronic distribution channels are very important tools. The research evidences the consolidation of electronic distribution as one of the main business tools currently used by the hotel sector.
\end{abstract}

KEYWORDS: Distribution Channels; Marketing; Hotel Management; Fortaleza. 


\section{Introdução}

As principais potências mundiais têm apresentado uma predominância do setor de serviços em suas economias. As principais economias do mundo estão dominadas pelos serviços, que em muitas vezes chegam a representar cerca de $70 \%$ do seu Produto Interno Bruto (PIB). A tendência é que o setor de serviços continue em franca expansão e em curva ascendente nas grandes potências mundiais (OSTROM et al., 2010). Esta realidade também reflete no Brasil, onde, segundo pesquisas recentes, o setor terciário tem impactado em aproximadamente $70 \%$ do PIB (BRASIL, 2013). Neste contexto, as empresas prestadoras de serviços têm buscado diferentes formas de fazerem com que seus produtos cheguem ao consumidor final. No setor hoteleiro não é diferente, e a utilização de canais de distribuição de modalidade direta ou indireta como ferramental de vendas de serviços é uma realidade. Ainda mais quando se verifica o amplo potencial turístico do Brasil, alavancado pela realização de grandes eventos internacionais no país, como a Copa do Mundo de 2014 e os Jogos Olímpicos de 2016 que, com certeza, acarretarão um crescimento significativo na rede hoteleira do Brasil.

Segundo O'Connor; Frew (2002) e Barbosa; Cancellier (2011), os hotéis tradicionalmente têm trabalhado com uma grande variedade de canais de distribuição. De modalidade direta ou indireta, os objetivos dos canais são os mesmos: atingir com mais rapidez os consumidores em potencial, transmitir informações com segurança e relevância para quem está comprando o serviço e proporcionar o máximo de conveniência para estes clientes. Recentemente, surgiram os canais eletrônicos de distribuição, funcionando como uma grande ferramenta de marketing para os profissionais do ramo hoteleiro. Para Buhalis (2000), e Barbosa; Cancellier (2011), com o crescimento da distribuição eletrônica, da utilização da internet e do avanço da tecnologia de informação, o mercado adquiriu um caráter mais dinâmico, trazendo vantagens tanto para quem compra como para quem vende o serviço. Diante do exposto, a presente investigação teve como objetivo analisar os canais de distribuição de modalidade direta ou indireta, assim como suas vantagens e desvantagens, utilizados pelo Hotel Casa de Praia, localizado na cidade de Fortaleza (CE). O presente trabalho enseja ainda verificar como funcionam as ações que resultam na prestação de serviços do referido hotel. A relevância acadêmica justifica-se diante da necessidade da realização de trabalhos e pesquisas que investiguem a temática, uma vez que a mesma consolidou-se como uma grande ferramenta de negócios utilizada no segmento hoteleiro. Segundo Buhalis (2010), a distribuição emergiu como uma das atividades mais dinâmicas da indústria do turismo e a tecnologia da informação possibilitou a implementação de novas formas de distribuição, o que impulsionou o surgimento de novos desafios ao setor.

A cidade de Fortaleza está localizada no estado do Ceará, na região Nordeste do Brasil. Conhecida internacionalmente como um grande centro receptor de turismo, Fortaleza possui aproximadamente dois milhões e quinhentos mil habitantes (SECRETARIA DE TURISMO DE FORTALEZA, 2013), e é a quinta capital do Brasil em número de habitantes. Cercada por atrativos naturais belíssimos, Fortaleza orgulha-se dos seus 34 quilômetros 
de belas praias conhecidas internacionalmente. Pela sua proximidade com a Europa, recebe uma grande quantidade de turistas oriundos de Portugal, Itália e França (PORTAL2014, 2013). Este trabalho de abordagem qualitativa, exploratória, teve como método de pesquisa a utilização de um estudo de caso que teve o Hotel Casa Praia como objeto de estudo. A pesquisa compõe-se de uma interconexão entre serviços, canais de distribuição e hotelaria evidenciados pelo referencial bibliográfico. Em seguida, é feita uma breve caracterização do objeto de estudo, apresentação dos resultados da entrevista semiestruturada e, por fim, são feitas as observações e análises referentes aos dados que foram apresentados sobre o Hotel Casa de Praia.

\section{Revisão da Literatura}

\section{A Predominância dos serviços nas principais economias mundiais}

Os serviços diferenciam-se dos bens físicos por possuírem características que os tornam únicos, ratificadas por diversos autores e constantemente referenciadas nas literaturas sobre a temática. São elas: intangibilidade, inseparabilidade, heterogeneidade e perecibilidade (VALARIE; PARASURAMAN; BERRY, 1985). Os serviços definitivamente assumem papel de destaque na atividade econômica de qualquer sociedade. Serviços de infraestrutura são primordiais para a construção do elo essencial entre todos os setores da economia, inclusive o cliente final. Em economias complexas e diversificadas, tanto os serviços comerciais quanto os de infraestrutura atuam como intermediários e também como canais de distribuição para 0 consumidor final (FITZSIMMONS; FITZSIMMONS, 2005; BARBOSA; HEINZE, 2012). Para um entendimento mais amplo deste fenômeno mundial, torna-se indispensável 0 entendimento do conceito de serviços, que, nas palavras de Gronroos (1990, p.27) é:

Uma atividade ou uma série de atividades de natureza mais ou menos intangível que normalmente, mas não necessariamente, ocorre entre consumidores e empregados de serviços e/ou recursos físicos ou bens e/ou sistemas do fornecedor do serviço, que são oferecidos como soluções para os problemas do consumidor.

$\mathrm{Na}$ definição de Ostrom et al., a ciência de serviço é definida como um campo emergente interdisciplinar "que incide sobre modelos, teorias e aplicações promovendo a inovação de serviços e gerando concorrência através da criação de valor" (OSTROM et al., 2010, p.5). Este significativo fenômeno global desencadeou uma série de discussões que interferem diretamente no funcionamento das empresas, na forma como desenvolvem as suas atividades, no bem-estar das sociedades e na qualidade de vida dos consumidores do mundo todo (BITNER; BROWN, 2008). O rápido crescimento do setor de serviços fez com que alguns estudiosos da área de marketing buscassem novas reflexões sobre a temática, inclusive sobre questões que estão diretamente relacionadas ao dinamismo do segmento, pois alguns pesquisadores afirmam que o mercado possui certa dificuldade 
para acompanhar o dinamismo apresentado pelos serviços (CARUSO, 1985).

\title{
Canais de distribuição na hotelaria
}

A rede hoteleira com frequência utiliza uma grande variedade de canais de distribuição para comercializar seus serviços. A maioria destes intermediários é constituída por agentes de viagens, operadoras de turismo ou empresas terceirizadas que representam estas redes em grandes centros receptores de turismo. Cada vez mais os hotéis vêm fazendo uso da grande quantidade de canais eletrônicos de distribuição que são disponibilizados no mercado, tendo a internet como grande ferramental de negócios (O'CONNOR; FREW, 2002).

O termo canal de marketing é derivado da palavra latina cannalis. De acordo com Lamb (2004), canal de marketing é uma estrutura empresarial de organizações independentes que vão do ponto de origem do produto até o consumidor, com a finalidade de mover o produto até o seu destino final de consumo, oferecendo alternativas para que o consumidor sinta-se à vontade em escolher os produtos ou serviços que mais sejam adequados às suas necessidades. Corroboram esta definição O'Connor e Frew (2002, p.33), afirmando que um canal de distribuição pode ser definido como "um mecanismo que proporciona informações suficientes para as pessoas certas, em momento e lugares apropriados, permitindo que as mesmas tomem a decisão de adquirir produtos e serviços". Megido (2002) entende que é importante ressaltar que a função dos canais de marketing limita-se à responsabilidade de vender produtos e facilitar o processo de chegada ao consumidor. Os canais de marketing não possuem funções precípuas de manuseio de produtos ou de financiamento dos mesmos. A distribuição, conforme Wahab et al. (1976, p.96), "é o que torna o produto disponível", pois cria a ligação entre fornecedores e consumidores de serviços turísticos, oferecendo informações que permitem aos consumidores efetivar e pagar as reservas. Nas palavras de Buhalis; Laws (2001, p.8),

\begin{abstract}
as funções primárias da distribuição para o turismo são informação, associação e organização de serviços de viagens. A maioria dos canais de distribuição, portanto, prestam informações para futuros turistas, unindo os produtos turísticos, e também estabelecendo mecanismos que permitam que os consumidores façam, confirmem e paguem pelas reservas.
\end{abstract}

Com relação ao surgimento dos canais de marketing no turismo, a distribuição no turismo urbano foi novamente negligenciada (O'CONNOR, 1999; PEARCE; TAN, 2002; BUHALIS; LAWS, 2001; DEL ALCÁZAR MARTÍNEZ, 2002). Grande parte das investigações tem sido feita em estudos em business-to-business, quando o foco está na incidência geográfica. Desta forma, este indicativo tem se baseado em dados mercadológicos em vez de considerar os dados do destino (PEARCE; TAN, 2002). As perspectivas do destino oferecem margem para que sejam analisadas de forma sistemática todas as diferenças e semelhanças com as 
estruturas do canal de distribuição e entre os setores e membros do canal. Os estudos "destinos orientados" que têm sido considerados vêm se centrando essencialmente no turismo de massa, que é fortemente dependente de pacotes desenvolvidos por operadores de viagem $(\mathrm{MARCH}$, 1996; BUHALIS, 2000; YAMAMOTO; GILL, 2002). De acordo com Carroll e Siguaw (2003); Barbosa e Cancellier (2010), a distribuição eletrônica de informação tem mudado os canais que as pessoas utilizam para realizar reservas, sendo que o desenvolvimento mais notável é que essas reservas que eram feitas por meio de agentes de viagens e centrais de reservas, agora são geradas on-line por clientes particulares e corporativos, mais susceptíveis ao uso de intermediários on-line ao contato direto com hotéis. Kotler e Armstrong (2003) explicam que os canais de distribuição podem ser classificados como diretos ou indiretos. Um hotel que utilize uma operadora para distribuir os seus serviços aos consumidores trabalha com canais de distribuição de modalidade indireta, ou seja, necessita de intermediação para que a venda seja finalizada. Quando na comercialização dos serviços não houver intermediários no canal de distribuição, diz-se que ele apresenta um sistema direto; caso contrário, configura-se como um sistema indireto de distribuição.

\section{Metodologia}

A busca por diferenciais que coadunem com a proposta da prestação de serviços com excelência, assim como a necessidade de tornar a empresa mais competitiva, fazem com que os hotéis encontrem no marketing subsídio que contribui para que alcancem seus objetivos junto aos seus clientes em potencial. Com base nesta reflexão, esta investigação teve como objetivo analisar os canais de distribuição utilizados pelo hotel Casa de Praia. De caráter eminentemente qualitativo e exploratório, na utilização do método recorreu-se a um estudo de caso. A metodologia empregada nesta pesquisa fundamenta-se nas proposições de Chizzotti (1991). Segundo o autor, as pesquisas qualitativas

\footnotetext{
[...] fundamentam-se em dados coligidos nas interações interpessoais, na coparticipação das situações dos informantes, analisadas a partir da significação que estes dão aos seus atos. O pesquisador participa, compreende e interpreta (CHIZZOTTI, 1991, p.52).
}

O estudo de caso é uma estratégia de pesquisa que foca na compreensão de dinâmicas que se encontram em um contexto singular, visando identificar padrões e inter-relações entre as variáveis existentes neste contexto, que permitam melhor entendimento de um determinado fenômeno (EISENHARDT, 1989; YIN, 2005). Eisenhardt (1989) afirma que o estudo de caso torna viável a elucidação sobre temáticas que ainda não tiveram propostas de estudos mais aprofundadas. Um dos preceitos básicos para a coleta de dados nos estudos de caso é, de acordo com Yin (2005), o uso de múltiplas fontes de evidências. Este autor comenta que, quando múltiplas fontes são incorporadas na investigação de um estudo de caso, por serem altamente complementares, aumentam consideravelmente sua 
qualidade. A coleta de dados desta investigação foi realizada a partir da realização de uma entrevista com o diretor e proprietário do hotel Casa de Praia. Um questionário semiestruturado subsidiou esta etapa. Durante o tratamento das informações, algumas lacunas necessitavam ser elucidadas. Em vista disso, o autor enviou um novo instrumento ao entrevistado para que as dúvidas encontradas pudessem ser esclarecidas. Após a devolução deste instrumento pelo entrevistado, o processo de tratamento e análise dos dados coletados pôde então ser concluído. Informações complementares foram obtidas através do website do hotel pesquisado.

\section{Apresentação dos dados da pesquisa}

\section{Caracterização do objeto de estudo}

O hotel utilizado como objeto de estudo desta investigação é classificado como de pequeno porte, categoria turística, localizado na cidade de Fortaleza, no estado do Ceará. O hotel possui 41 apartamentos, aproximadamente 100 leitos, equipados com TV a Cabo, internet, ar condicionado, cofres e frigobar. Ainda são disponibilizados aos hóspedes: lavanderia, room service, garagem e uma piscina localizada na cobertura do hotel. Atualmente a staff do hotel é composta por 14 funcionários e dois diretores. O hotel Casa de Praia possui uma excelente localização, situado na Praia de Iracema, próximo a lojas, farmácias, bares e restaurantes. Segundo o seu diretor e proprietário, o hotel mantém altas taxas de ocupação durante 0 ano todo, tendo como foco os diferenciais no atendimento e qualidade nos serviços que são disponibilizados aos seus clientes.

\section{Resultados da pesquisa}

O Hotel Casa de Praia apresenta características peculiares de empreendimentos hoteleiros, que buscam satisfazer seus clientes através do excelente atendimento e também fazendo uso dos conceitos difundidos nos fundamentos da hospitalidade. Este modelo de serviços deve-se à proposta a qual é utilizada pelo hotel para contratação e manutenção da sua staff.

Segundo o diretor e proprietário do hotel, atualmente não existem dificuldades em contratar colaboradores para desenvolverem serviços especializados no hotel. Por ser um destino predominantemente turístico, a oferta de mão de obra qualificada para atuar nos segmentos turísticos e hoteleiros é grande. O entrevistado explicou ainda que todos os colaboradores do hotel recebem um treinamento antes de assumirem suas funções na empresa. Para o entrevistado, a política de gestão adotada pelo hotel que envolve os seus colaboradores contribui para o sucesso e desenvolvimento da empresa. Segundo o entrevistado, os colaboradores do hotel possuem participação nos lucros, salários compatíveis com o mercado e um excelente ambiente de trabalho, o que acaba resultando em profissionais plenamente satisfeitos, procurando desenvolver suas funções com excelência, além de fazer com que praticamente não exista uma 
grande rotatividade de colaboradores, o que vem a ser muito bom para a empresa.

Outro fator apontado pelo entrevistado que explica as grandes taxas de ocupação do hotel, é o fato de que em um mercado tão competitivo como é a hotelaria, os clientes que se hospedam no Hotel Casa de Praia sempre conseguem visualizar como muito positivo o custo/benefício encontrado na aquisição daquele serviço. O entrevistado explicou que a empresa utiliza para fazer a distribuição de seus serviços canais de marketing de modalidade direta e indireta. Contudo, a predominância encontra-se nos canais de distribuição eletrônicos, pois, segundo o entrevistado, a internet, assim como as principais ferramentas eletrônicas disponibilizadas no mercado, funciona como grande ferramental de negócios. O diretor da empresa explicou que para o hotel não existe período de baixa estação. A empresa mantém altos índices de ocupação durante o ano inteiro, o que representa aproximadamente $90 \%$ de ocupação durante quase todo o ano, com exceção dos meses de abril e maio, quando a taxa de ocupação fica em torno de $70 \%$ (segundo informação verbal disponibilizada pelo diretor do Hotel Casa de Praia em 09 de janeiro de 2013), que tem como principais clientes representantes comerciais, empresas e hóspedes habituais que viajam em férias.

Os principais canais de distribuição utilizados pelo hotel são: o website do hotel, agências de viagens, os sites de busca Booking e Decolar e clientes que propagam os serviços do hotel caracterizando a propaganda "boca a boca". O entrevistado salientou que com a estrutura que possui hoje não seria possível atender a todos se utilizasse uma quantidade maior de canais de distribuição. O diretor do hotel pontuou ainda que o grande problema da sua estrutura é que ela não atende mais as necessidades do hotel, e que se tivesse uma quantidade maior de apartamentos e leitos disponíveis, os mesmos seriam ocupados. A Figura 1 ilustra os principais tipos de canais de distribuição utilizados pelo Hotel Casa de Praia.

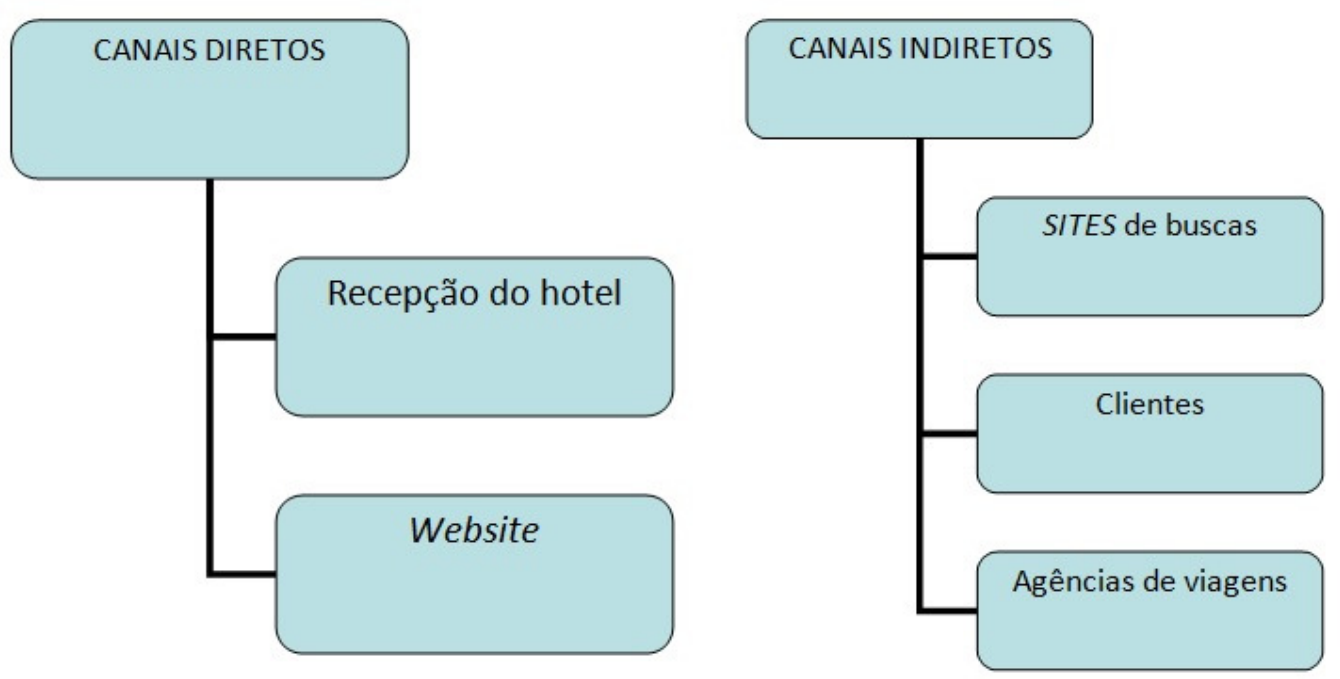

Figura 1: Canais de distribuição utilizados pelo Hotel Casa de Praia.

Fonte: Dados da pesquisa.

Figure 1: Distribution channels used by the Beach House Hotel. Source: Research data. 
Para o entrevistado, existem vantagens e desvantagens tanto na utilização de canais de distribuição de modalidade direta, como nos de distribuição indireta. A tabela 01 sintetiza os percentuais referentes à utilização de cada canal, assim como da respectiva modalidade.

Tabela 1: Percentagens dos canais de distribuição utilizados pelo Hotel Casa de Praia.

Fonte: elaborado pelo autor.

Table 1: Percentages of distribution channels used by the Beach House Hotel.

Source: prepared by the author.

\begin{tabular}{|c|c|c|}
\hline Tipo de Canais & Modalidade & $\begin{array}{c}\text { Percentual das } \\
\text { Reservas }\end{array}$ \\
\hline Recepção do hotel & Direta & $10 \%$ \\
\hline Sites de buscas & Indireta & $20 \%$ \\
\hline Website do hotel & Direta & $50 \%$ \\
\hline Clientes & Indireta & $15 \%$ \\
\hline Agências de viagens & Indireta & $5 \%$ \\
\hline
\end{tabular}

Conforme se verifica pelos dados apresentados, é predominante a utilização de canais de distribuição de modalidade direta representada pelas reservas efetuadas via website do hotel (50\%). Em segundo lugar aparecem os sites de busca (Decolar, Booking e hotéis.com), que respondem por $20 \%$ do total de reservas efetuadas pelo hotel. Os outros números correspondem às vendas efetivadas via recepção do hotel (10\%) e aos clientes que chegam ao hotel através de outros clientes (boca a boca) totalizando 15\% de todas as reservas efetuadas e, por fim, as agências de viagens, que respondem pelo percentual de $5 \%$ das reservas efetuadas.

\section{Análise dos dados coletados}

Os resultados desta investigação indicam que os canais de distribuição vêm sofrendo grandes modificações nos últimos anos, o que resulta em uma imposição de um novo meio de gestão que se impõe ao setor hoteleiro, pois, uma vez que o empreendimento não se adapta a esta nova realidade, com certeza terá problemas na comercialização de seus serviços. Uma coisa é fato: os canais de distribuição sempre tiveram um papel relevante na indústria do turismo, isso é possível verificar desde os primeiros pacotes organizados por Thomas Cook no século XIX. Para Buhalis (2000), a distribuição eletrônica tem emergido como uma das principais ferramentas de competitividade na indústria do turismo, tendo a tecnologia de informação como grande recurso, que torna mais dinâmico o processo de comercialização de serviços turísticos, proporcionando riscos e oportunidades aos participantes do processo. O hotel objeto de estudo desta investigação localiza-se em um grande núcleo receptor de turismo, e 
procura investir em diferenciais que relacionados diretamente à prestação dos serviços oferecidos, o que o torna mais competitivo no mercado.

O hotel Casa de Praia utiliza canais de distribuição de modalidade direta e indireta, sendo que a predominância dos canais de distribuição de modalidade eletrônica direta chamou atenção nos dados apresentados. $O$ fato de um hotel de pequeno porte concentrar suas vendas em canais de distribuição eletrônicos apenas ratifica a predominância deste ferramental, já salientado pelos autores no referencial teórico apresentado. Com relação à utilização de canais de distribuição de modalidade direta, a principal vantagem verificada é que sobre as vendas realizadas através desta modalidade não incidem comissões para os intermediários. Outra vantagem é a possibilidade de estabelecer um vínculo com o cliente, pois a partir da troca de e-mails fica estabelecida uma relação mais próxima entre empresa e cliente, e as vendas realizadas através da recepção do hotel permitem que os colaboradores do hotel efetuem a venda com segurança, pois os mesmos possuem domínio do serviço que está sendo oferecido. Para esta modalidade de distribuição não foram apresentadas desvantagens. As principais vantagens atribuídas aos canais de modalidade indireta foram: o cliente que recebe a indicação de outro chega ao hotel com muita segurança, porque já possui um referencial do serviço que será oferecido, e o fato do hotel não ter de pagar comissões aos clientes que realizaram a indicação por terem ficado satisfeitos com a empresa também foi considerado uma vantagem. A grande fragilidade apontada para esta modalidade de distribuição é o fato de que a abrangência deste canal atinge poucas pessoas.

Com relação aos sites de buscas, considerados o segundo canal mais utilizado pelo hotel, verificou-se como as principais vantagens o fato que estes sites possuem um alcance muito grande, sua abrangência acontece em nível nacional e internacional; também foi apontado como vantagem $o$ fato de que estes sites de buscas geralmente oferecem aos clientes a possibilidade de terem contato com avaliações deixadas pelos clientes que já passaram pelo hotel, o que, além de ser uma excelente propaganda para a empresa, também funciona como termômetro para que a direção do hotel avalie como os serviços estão sendo prestados e corrija eventuais falhas. As desvantagens ficam por conta de que a empresa obriga-se a pagar comissões que variam entre $10 \%$ e $15 \%$, além de que, para o entrevistado, na maioria das vezes o cliente estabelece um vínculo com o canal de distribuição (site que indica o serviço) e não reconhece o hotel como o elemento principal desta relação. Diante do exposto, percebese que o hotel concentra a distribuição de seus serviços em canais eletrônicos de distribuição de modalidade direta e procura estabelecer parcerias com empresas sérias e confiáveis, representadas nesta pesquisa pelos sites de buscas, ainda que esta parceria seja estabelecida diante de pagamento de comissões. A Tabela 2 resume as vantagens e desvantagens verificadas na pesquisa: 
Tabela 2: Vantagens e desvantagens nas modalidades direta e indireta.

Fonte: Elaborada pelo autor.

Table 2: Advantages and disadvantages in direct and indirect ways.

Source: Prepared by the author.

\begin{tabular}{|l|l|l|l|}
\hline $\begin{array}{l}\text { Distribuição } \\
\text { Direta } \\
\text { (Vantagens) }\end{array}$ & $\begin{array}{l}\text { Distribuição } \\
\text { Direta } \\
\text { (Desvantagens) }\end{array}$ & $\begin{array}{l}\text { Distribuição Indireta } \\
\text { (vantagens) }\end{array}$ & $\begin{array}{l}\text { Distribuição Indireta } \\
\text { (desvantagens) }\end{array}$ \\
\hline $\begin{array}{l}\text { - Cria-se vínculo } \\
\text { com o cliente. } \\
- \text { O serviço é } \\
\text { vendido com } \\
\text { segurança. }\end{array}$ & Não há & $\begin{array}{l}\text { Contato direto com o } \\
\text { cliente. O cliente sente- } \\
\text { se mais seguro em } \\
\text { contratar diretamente } \\
\text { com a empresa }\end{array}$ & $\begin{array}{l}\text { Pagamentos de } \\
\text { comissões com } \\
\text { percentuais entre } \\
10 \% \text { e 15\%. }\end{array}$ \\
\hline $\begin{array}{l}\text { Não incide } \\
\text { pagamento de } \\
\begin{array}{l}\text { comissões a } \\
\text { intermediários. }\end{array}\end{array}$ & Não há & $\begin{array}{l}\text { Grande abrangência } \\
\text { (quando realizada pelos } \\
\text { sites de buscas). }\end{array}$ & $\begin{array}{l}\text { Pequena abrangência } \\
\text { (quando realizada por } \\
\text { clientes). } \\
\text { O vínculo é criado } \\
\text { com o intermediário e } \\
\text { não com o hotel. }\end{array}$ \\
\hline
\end{tabular}

\section{Considerações finais}

O destino turístico Fortaleza possui uma característica marcante que o torna diferente de outros centros receptores de turismo. As excelentes condições climáticas, que propiciam sol e calor o ano inteiro, fazem com que este destino não seja atingido por uma forte sazonalidade. Dadas estas condições, a quantidade de empreendimentos hoteleiros na cidade é considerada alta, o que faz com que as empresas atuantes naquele mercado busquem alternativas diferenciadas e de grande alcance para disseminarem os seus serviços. Excelência na prestação dos serviços oferecidos passa a ser pré-requisito obrigatório para as empresas que desejam manter-se em um mercado tão competitivo. Os canais de marketing, sejam eles de modalidade direta ou indireta, aparecem como as grandes ferramentas que auxiliam as empresas hoteleiras na comercialização de serviços. Esta pesquisa teve como objetivo analisar os canais de distribuição utilizados pelo Hotel Casa de Praia, assim como verificar as vantagens e desvantagens de cada modalidade. A pesquisa alcançou o seu objetivo a partir de quando verificada a predominância da utilização de canais de distribuição de modalidade direta de forma eletrônica. Os resultados ratificam o pensamento de Carrol e Siguaw (2003), quando afirmam que a distribuição eletrônica tem mudado os canais que as pessoas utilizam para fazer reservas facilitando a distribuição direta do consumidor ao fornecedor. Os dados apresentados sugerem que os canais de distribuição são utilizados pela empresa de acordo com o público que a mesma deseja alcançar. Por fim, sugere-se a realização de novos trabalhos que envolvam esta temática, fazendo uso de hotéis de grande porte e de diferentes localidades turísticas do Brasil.

\section{Referências bibliográficas}

BARBOSA, F.S.; HEINZE, R.S.S. Análise do planejamento logístico de restaurantes: um estudo de caso dos restaurantes de São Borja/RS. Anais do 12을 Encontro Nacional de Turismo de Base Local - ENTBL, São Paulo, 2012. 
BARBOSA, F.S; CANCELLIER, E. L.P de L. Análise dos canais de distribuição em Hotel de pequeno porte em Balneário Camboriú (SC). Revista eletrônica de Estratégia e Negócios. V.4, n.1, jan./jun. p.3-18, 2011. Disponível em: $<$ http://portaldeperiodicos.unisul.br/index.php/EeN/article/view/475 $>$. Acesso em: 20 jan. 2013.

BITNER, M. J.; BROWN, S. W. The Service Imperative. Business Horizons. Indiana. V. 51 (January - February) P. 39-46, 2008. Disponível em: $<$ http://www.sciencedirect.com/science/article/pii/S0007681307001097>.

Acesso em: 20 jan. 2013.

BRASIL.<http://www.brasil.gov.br/sobre/economia/setores-daeconomia/comercio-e-servicos. > Acesso em 28 jan. 2013.

BUHALIS, D. Relationships in the Distribution Channel of Tourism: conflicts between hoteliers and tour operators in the mediterranean region. Global Alliances In Tourism And Hospitality Management. Surrey, UK. v. 1, p. 113139, 2000. Disponível em: <http://epubs.surrey.ac.uk/1082/1/fulltext.pdf >. Acesso em 28 jan. 2013.

BUHALIS, D.; LAWS, E. Tourism Distribution Channel: Practices, Issues and Transformations. London: Continuum. 2001.

CARROL, B; SIGUAW, J. The Evolution of Electronic Distribution: effects on hotels e intermediaries. In: Cornell Hotel and Restaurant Administration Quartely. Cornell, UK. p 38-50, 2003. Disponível em: <http://cqx.sagepub.com/content/44/4/38.citation>. Acesso em 28 jan. 2013.

CARUSO, T. E. Nascent Field of Service Marketing offers opportunities. Marketing News. (Collegiate Edition). V. 3 (January): 7, American Marketing Association, 1985.

CHIZZOTTI, A. Pesquisa em ciências humanas e sociais. São Paulo: Cortez, 1991.

DEL ALCÁZAR MARTÍNEZ, D. B. Los Canales de Distribución en el Sector Turístico. Madrid: ESIC Editorial, 2002.

EISENHARDT, K, M. Building Theories from case study research. Academy of management. v. 14, p. 532-550. Wallingford: CABI Publishing, 1989.

FITZSIMMONS, James A.; FITZSIMMONS, M. J.. Administração de Serviços: operações, estratégia e tecnologia da informação. 4a $\mathrm{Ed}$. Porto Alegre: Bookman, 2005.

GRONROOS, C. Service management and marketing. London: Lexington Books, 1990.

KOTLER, P.; ARMSTRONG, G. Princípios de Marketing. São Paulo: PrenticeHall, 2003.

LAMB, C. W. Princípios de marketing. São Paulo: Learning, 2004.

$\mathrm{MARCH}, \mathrm{R}$. 'Organisational Linkages in Australia's Japanese Inbound Travel Market,' in G. Prosser (ed). Tourism and Hospitality Research: Australian Travel and Hospitality. Sydney: SAGE Editions, 1996.

MEGIDO, J. L. T. Administração de vendas e canais de distribuição. São Paulo: Atlas, 2002. 
OSTROM, M. J; BITNER, S. W.; BROWN, K. A. BURKHARD, M. G., SMITHDANIELS, V. HALUK, D. and RABINOVITCH, E. Moving Forward and Making a Difference: Research Priorities for the Science of Service: L. Journal of Service Research. Maryland. P 5-35, 2010. Disponível em: <http://jsr.sagepub.com/content/13/1/4.full.pdf+html>. Acesso em 28 jan. 2013.

O'CONNOR, P. Electronic Information Distribution in Tourism and Hospitality. Wallingford. CABI Publishing, 1999. P. 48-50.

O'CONNOR, P.; FREW, J. A. The Future of Hotel Electronic Distribution: expert and industry perspectives. In: Cornell Hotel and Restaurant Administration Quarterly. $\quad$ p. 35-43, $2002 . \quad$ Disponível em: $<$ http://www.sciencedirect.com/science/article/pii/S0010880402800167 >. Acesso em 20 jan. 2013.

PEARCE, D. G.; TAN, R. Tan. Tourism Distribution Channels: a Destination Perspective. New Zealand Tourism and Hospitality Research Conference. p. 242-250. 2002.

PEARCE, D.; TAN, R.; SCHOTT, C. Tourism Distribution Channels in Wellington. New Zealand: International Journal of Tourism Research, 2004.

PORTAL 2014. <http://www.portal2014.org.br/cidades-sedes/FORTALEZA/>. Acesso em 14 de abril de 2014.

SECRETARIA DE TURISMO DE FORTALEZA. Disponível em: $<$ http://www.fortaleza.ce.gov.br/turismo/aspectosdemograficos $>$ Acesso em 28 jan. 2013.

VALARIE, A. Z; PARASURAMAN, A.; BERRY, L.L. Problems and Strategies in Service Marketing. Journal of Marketing, v. 49 - 33-46. 1985.

WAHAB, S., CRAMPON, L. J.; ROTHFIELD, L. M. Tourism Marketing. Tourism. p. 76-78. 1976.

YAMAMOTO, D; GILL, A. Issues of globalisation and reflexivity in the Japanese tourism production system: the case of Whistler, British Columbia. The professional geographer. V. 54, p. 83-93. 2002.

YIN, R. K. Estudo de Caso: planejamento e métodos. Porto Ale: Bookman, 2005.

Fabrício Silva Barbosa: Instituto Federal Farroupilha, São Borja, RS, Brasil.

E-mail: fbarbosa@sb.iffarroupilha.edu.br

Link para o currículo Lattes: http://lattes.cnpq.br/7960325589026879

Data de submissão: 31 de janeiro de 2014

Data de recebimento de correções: 05 de maio de 2014

Data do aceite: 05 de maio de 2014

Avaliado anonimamente 